ORIGINAL ARTICLE

\title{
Intussusception and rotavirus associated hospitalisation in New Zealand
}

\author{
Y E Chen, S Beasley, K Grimwood, and the New Zealand Rotavirus Study Group
}

Arch Dis Child 2005;90:1077-1081. doi: 10.1136/adc.2005.074104

See end of article for authors' affiliations

....................

Correspondence to: Prof. K Grimwood, Department of Paediatrics and Child Health, Wellington School of Medicine and Health

Sciences, PO Box 7343,

Wellington $6015, \mathrm{New}$

Zealand; grimwood@

wnmeds.ac.nz

Accepted 7 June 2005

Published Online First

17 June 2005

\begin{abstract}
Aims: To describe the epidemiology of intussusception and its relation to rotavirus associated hospitalisation in New Zealand.

Methods: National hospital discharge data between January 1998 and June 2003 for all children younger than 3 years of age with intussusception were reviewed. Independently, children from the same age group, admitted to eight paediatric units with rotavirus gastroenteritis between May 1998 and May 2000, were identified prospectively. Epidemiological characteristics of cases with intussusception were compared with those of hospitalised rotavirus disease.

Results: During the 5.5 year study period, there were 277 cases of intussusception and no deaths. Most $(72 \%)$ occurred in the first year of life (age adjusted incident rate 65 per 100000 child-years, $95 \% \mathrm{Cl} 56$ to 74 ). Risk of intussusception was less in females (risk ratio $0.58 ; 95 \% \mathrm{Cl} 0.43$ to 0.78 ) and for Maori (risk ratio $0.52 ; 95 \% \mathrm{Cl} 0.35$ to 0.77 ) when compared with European infants. In contrast to hospitalised rotavirus cases, intussusception peaked at a younger age and lacked seasonality.

Conclusions: This study provides national baseline data on intussusception for future rotavirus vaccine programmes in New Zealand. Wild-type rotaviruses do not appear to have a major role in triggering intussusception. Prospective surveillance systems, using standardised case definitions and nested casecontrol methodology, are needed to further our understanding of the aetiology and epidemiology of intussusception.
\end{abstract}

ntussusception, the most common cause of acute intestinal obstruction in infants and young children, occurs when one segment of bowel invaginates into adjacent distal segments, resulting in venous congestion and bowel wall oedema. Eventually, obstruction of the arterial blood supply may lead to bowel infarction, perforation, septicaemia, and even death. ${ }^{1}$ Mostly the cause is unknown, with anatomical abnormalities triggering intussusception identified in fewer than $10 \%$ of cases, and then mainly in older children. ${ }^{12}$ The frequent association of intussusception with hypertrophy of Peyer patches and mesenteric lymphadenopathy raises the possibility of an infectious cause. In particular, adenoviruses are implicated, as they have been found in intestinal and mesenteric lymph node tissue, and in oropharyngeal and rectal swabs of children with intussusception. ${ }^{2-4}$

Rotaviruses are the most common cause of severe diarrhoea in young children, causing more than 600000 deaths annually worldwide, mainly in developing countries. ${ }^{5}$ While diarrhoea related deaths in New Zealand are rare, more than 1100 children are hospitalised annually with rotavirus disease. ${ }^{6}$ Efforts at prevention received a setback when the first licensed rotavirus vaccine, rhesus-human reassortant tetravalent vaccine (RRV-TV; Rotashield; Wyeth-Ayerst), was withdrawn because of its association with intussusception, particularly within two weeks of the first dose. ${ }^{7-9}$ This highlighted our limited understanding of intussusception and prompted a re-examination of the role wild-type rotaviruses might play in its causation. While three small, uncontrolled case series from Japan, ${ }^{10}$ France, ${ }^{11}$ and Australia $^{12}$ produced conflicting results when identifying rotaviruses in children with intussusception, recent population based studies from the United States found no such association. ${ }^{81314}$ Nonetheless, rotaviruses capable of inducing intussusception remain biologically plausible since sonography during rotavirus infection shows increased thickness of the wall of the distal ileum and mesenteric lymphadenopathy. ${ }^{15}$ The RRV-TV experience highlighted gaps in our knowledge of intussusception's aetiology and global epidemiology. ${ }^{216}$ Regional differences in rates of intussusception exist, but whether these result from differential reporting or genetic, ethnic, infectious, or environmental factors is unknown.

Currently, information on intussusception in New Zealand is limited to recent studies describing management ${ }^{17}{ }^{18}$ and a retrospective case series published more than 20 years ago from a single hospital. ${ }^{19}$ As national data are lacking we first sought to describe the epidemiology of intussusception and then to define its relation to rotavirus associated hospitalisation by performing population based studies utilising two independent databases. The analysis focuses on children younger than 3 years of age who account for $85-90 \%$ of intussusception cases and rotavirus disease during childhood. ${ }^{120-23}$ This study provides national baseline data for surveillance, should it be required in the immediate postlicensure period of future live attenuated rotavirus vaccines, and adds to our understanding of the global epidemiology of intussusception.

\section{METHODS}

Data from the New Zealand Health Information Service (NZHIS) for all public hospitals were reviewed to identify children younger than 3 years of age with a discharge diagnosis of intussusception (ICD-10 AM code K561) between January 1998 and June 2003. Searches of paediatric surgical and radiology databases and discharge coding at Christchurch and Wellington public hospitals were followed by case record review to confirm the diagnosis according to standard radiographic or surgical findings. ${ }^{17}$ Interhospital

Abbreviations: NZHIS, New Zealand Health Information Service; RRR-TV, rhesus-human reassortant tetravalent vaccine 


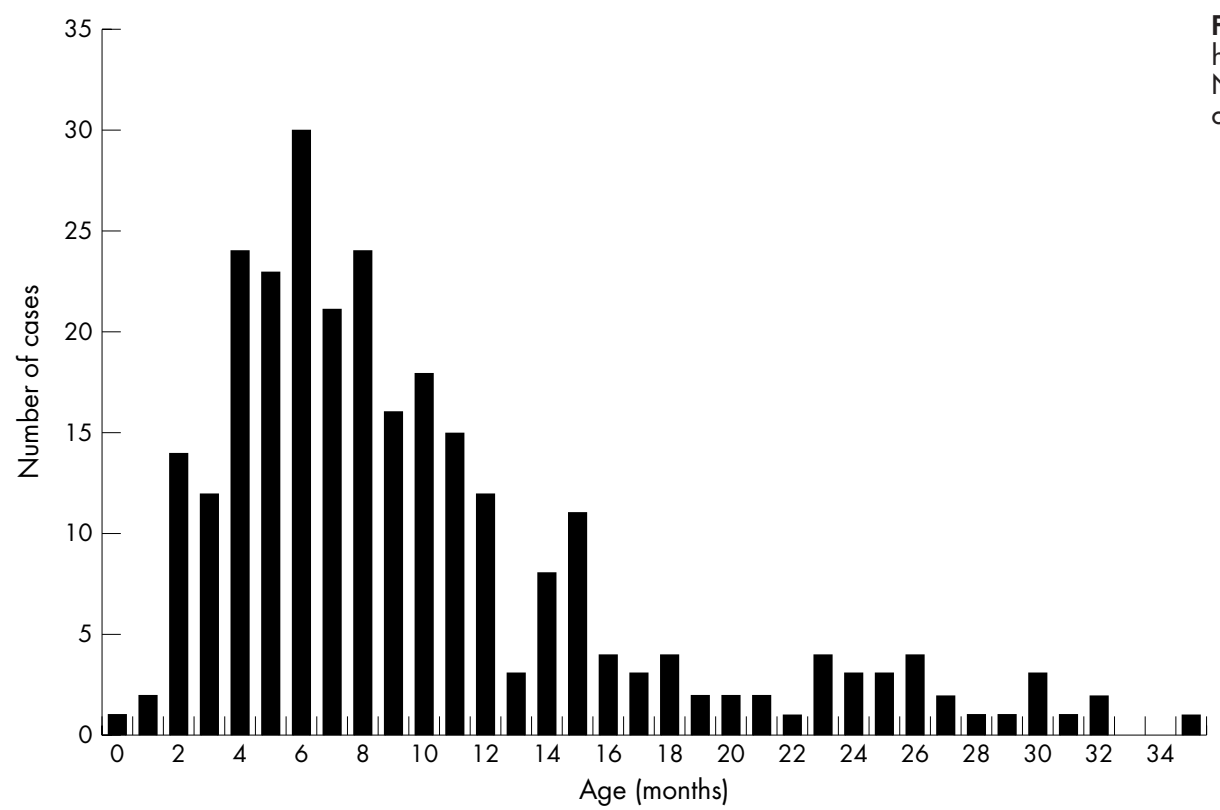

Figure 1 Age distribution of hospitalised intussusception cases in New Zealand children less than 3 years of age, January 1988 to June 2003.

transfers and readmissions within a week of the original presentation were counted as a single episode.

The NZHIS provided data on age, gender, single prioritised (Maori, Pacific, Asian, other, European) ascribed ethnicity from parent or caregiver, ${ }^{24}$ region, and month and year of presentation. Incidence rates were calculated using age specific population estimates from Statistics New Zealand 1996 and 2001 census data (http://www.stats.govt.nz/). As intussusception is a relatively rare outcome, $95 \%$ confidence intervals for incidence rates and their ratios were calculated using standard methods based on the Poisson distribution.

Data from a prospective surveillance study measuring the burden of rotavirus disease in New Zealand (manuscript submitted) were used to compare age and seasonal distributions for hospitalisation of intussusception and rotavirus gastroenteritis. Children younger than 3 years of age admitted to any one of eight paediatric units in five major metropolitan regions with acute gastroenteritis between May 1998 and April 2000 had faecal samples sent for rotavirus enzyme linked immunosorbent assays (ELISA, Dako Cytomation Ltd, UK) at a central laboratory. These hospitals serviced 65\% (21\% Maori, 11\% Pacific, 68\% European/other) of the 0-3 year old national cohort and were broadly representative of the New Zealand population for this age group.

The Canterbury and Wellington Regional Ethics Committees approved the study.

\section{RESULTS}

During the 5.5 year study period, 32 lchildren aged $0-14$ years were coded in the NZHIS database with a discharge diagnosis of intussusception. Of these, 277 (86\%) were younger than 3 years of age. NZHIS detected 96/101 (95\%) cases identified by local audit at Christchurch and Wellington Hospitals. Chart review found $78 / 83$ (96\%) cases younger than 3 years of age were correctly coded as intussusception. No deaths were recorded.

Cases among children younger than 3 years of age numbered 41-61 per year. There was however no evidence of annual or seasonal trends. The age distribution for intussusception is shown in fig 1 . The data were negatively skewed, with $200(72 \%)$ cases presenting in the first year of life. Median age was 8 (interquartile range (IQR) 5-12) months and highest incidence rates were found in infants (table 1).

Since most cases of intussusception occur during the first year of life, and as this is the target age group for rotavirus immunisation, the subgroup analyses presented in table 2 focus solely on infants. Nevertheless, similar results were found when older children were included in the analysis (data not shown). Sixty five per cent of cases were in boys, resulting in a male:female ratio of 1.82. Compared with Europeans, intussusception was least common in Maori infants, even after multiple ethnicities were included in expanded population denominators and the data reanalysed (risk ratio $0.57 ; 95 \%$ CI 0.39 to 0.83 ). No regional differences were detected.

Independently, between May 1998 and May 2000, rotaviruses were prospectively identified in 485/1138 (43\%) children younger than 3 years of age hospitalised with acute gastroenteritis. Figure 2 shows partial overlapping age distributions between intussusception and hospitalised rotavirus

Table 1 Incidence rate estimates and $95 \%$ confidence intervals (Cl) of intussusception in New Zealand children younger than 3 years of age between January 1998 and June 2003

\begin{tabular}{lllll}
\hline Age group & Cases & Population* $^{*}$ & Incidence & $95 \% \mathbf{C l}$ \\
\hline$<1$ year & 200 & 306994 & 65 & (56 to 75$)$ \\
$1-2$ years & 56 & 308413 & 18 & (14 to 24$)$ \\
$2-3$ years & 21 & 312208 & 6.7 & (4.2 to 10) \\
Total & 277 & 927615 & 30 & (26 to 34) \\
\hline
\end{tabular}

*Exposed age adjusted population for the 5.5 year period. tPer 100000 child-years. 
Table 2 Incidence estimates, rate ratios, and confidence intervals $(\mathrm{Cl})$ of intussusception for sex, ethnicity, and region in infants $<12$ months of age between January 1998 and June 2003

\begin{tabular}{|c|c|c|c|c|c|c|c|}
\hline & Cases & Population* & Incidence $†$ & $95 \% \mathrm{Cl}$ & Rate ratio & $95 \% \mathrm{Cl}$ of rate ratio & p value \\
\hline Gender & $(n=200)$ & & & & & & \\
\hline Male & 129 & 157322 & 82 & (68 to 96$)$ & 1.0 & & \\
\hline Female & 71 & 149666 & 47 & (36 to 58$)$ & 0.58 & (0.41 to 0.75$)$ & 0.002 \\
\hline Ethnicity $\ddagger$ & $(n=194)$ & & & & & & \\
\hline European & 125 & 165325 & 76 & (62 to 89$)$ & 1.0 & & \\
\hline Maori & 34 & 86174 & 39 & (26 to 53 ) & 0.52 & (0.32 to 0.72 ) & 0.004 \\
\hline Pacific & 22 & 32676 & 67 & (39 to 95 ) & 0.89 & (0.49 to 1.29 ) & 0.63 \\
\hline Asian & 13 & 20696 & 63 & (29 to 97$)$ & 0.83 & (0.36 to 1.31$)$ & 0.54 \\
\hline Region & $(n=199)$ & & & & & & \\
\hline North Island & 152 & 244525 & 62 & (52 to 72$)$ & 1.0 & & \\
\hline South Island & 47 & 62464 & 75 & (54 to 97$)$ & 1.21 & (0.81 to 1.61$)$ & 0.26 \\
\hline
\end{tabular}

*Exposed age adjusted population for the 5.5 year period.

†Per 100000 child-years.

$\ddagger 2123$ children of "other" ethnicity not included.

cases. However, the peak age for children with rotavirus occurred four months later in infancy, with a median age of 12 (IQR 8-20) months (Mann Whitney test, p < 0.0001). By plotting the monthly percentage of total hospitalisations for intussusception and for rotavirus disease in fig 3, the lack of seasonality seen with intussusception contrasted sharply with the consistent winter peak for rotavirus hospital admissions. The two small peaks of intussusception cases in March and October probably represent random fluctuations in small numbers, as peaks in these months were present in only two of the five years surveyed.

\section{DISCUSSION}

Risk estimates of approximately 1 in 10000 RRV-TV recipients developing intussusception have profoundly influenced rotavirus vaccine development. ${ }^{16}{ }^{25}$ As rates vary between regions, several countries are establishing their own intussusception incidence data as a basis for postlicensure surveillance for the next generation of rotavirus vaccines. The main focus of surveillance should be on infants since they are at greatest risk of intussusception and are the likely target group of rotavirus vaccine programmes. Estimated incident rates in New Zealand infants appear similar to those from England (66 per 100000$),{ }^{26}$ but are slightly higher than the United States (18-56 per
100 000), ${ }^{142728}$ Central and South America (Panama 30, Venezuela 35, Chile 55 per 100000 respectively $)^{29-31}$ and slightly lower than in Hong Kong (89 per 100 000). ${ }^{32}$ The rate of intussusception in the current study did not vary significantly from year to year. However, surveys conducted over longer periods in the United States, Denmark, and Australia report decreased rates during the 1990s. ${ }^{27}{ }^{33} 34$ The reasons for these decreases are unclear, although different populations, data sources, coding classifications, and medical practice may have played a role. Although such factors are not apparent in the Danish study, ${ }^{33}$ comparing incidence rates between countries should be undertaken cautiously because rates may vary within populations and at different times.

The epidemiology of intussusception in New Zealand is nevertheless consistent with published studies from several different settings. Male predominance is reaffirmed and although more than half the cases occur during infancy, intussusception is uncommon during the first two months of life, even in developing countries where peak rates are found before 6 months of age. ${ }^{21426-32}$ The low rate of intussusception among very young infants might be related to factors such as immaturity of intestinal lymphoid tissue, passive protection against infectious agents by maternal antibodies and from breast feeding, and the low antigenic diversity of their diet. ${ }^{27}$

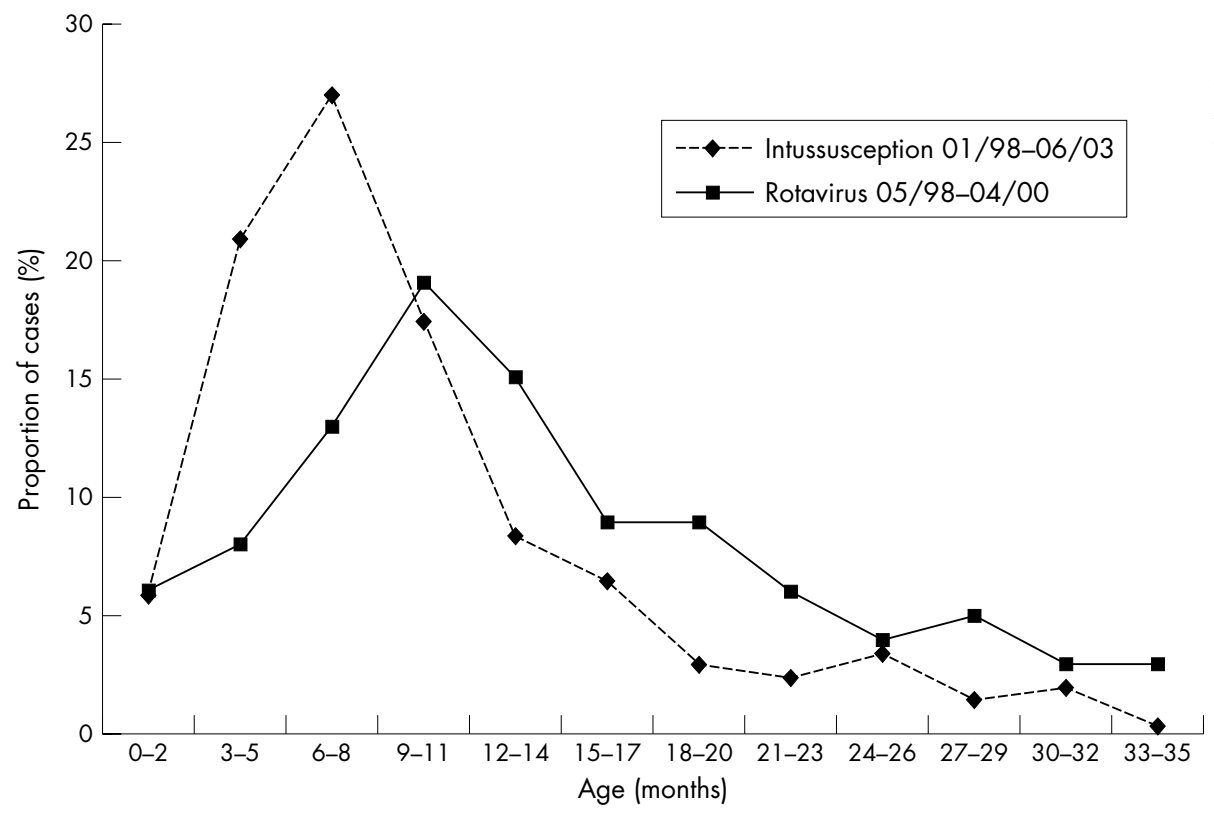

Figure 2 Age distribution for intussusception and rotavirus gastroenteritis hospitalisations in New Zealand children younger than 3 years of age. 


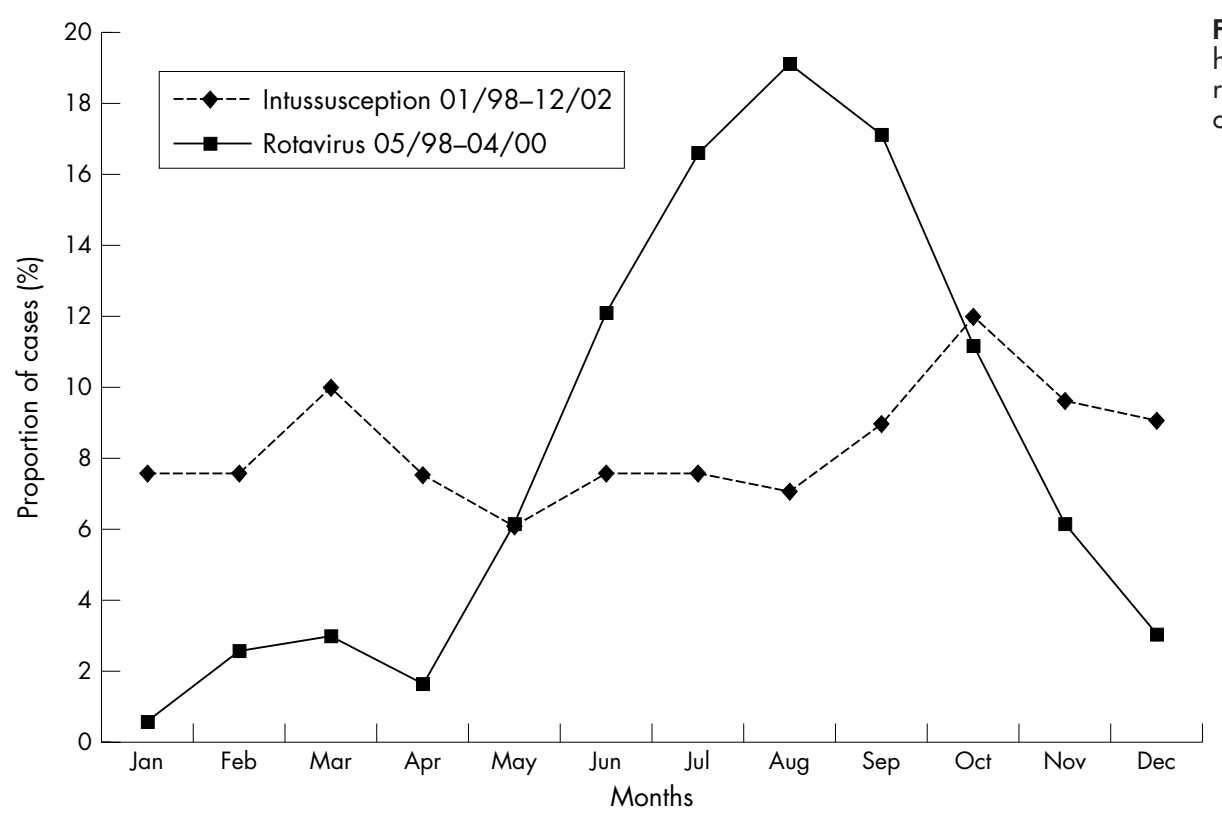

Figure 3 Seasonal distribution of hospitalisation for intussusception and rotavirus disease in New Zealand children aged less than 3 years.

Studies from the United States report higher rates of intussusception among black and Hispanic infants. ${ }^{97}$ However, in Panama and Venezuela where the population is predominantly Hispanic, a lower incidence of intussusception than in many developed countries is found. ${ }^{29}{ }^{30}$ Thus when rates of intussusception are compared between different regions, the influence of ethnicity may be complex, incorporating unidentified genetic, cultural, and environmental factors. The present study found a lower incidence among Maori infants than other ethnic groups in New Zealand. Lower rates have also been reported in native American Indians following improvements in water, sanitation, and health care, ${ }^{27}$ and for unexplained reasons in indigenous Australians ${ }^{34}$ and among Arab children in Israel. ${ }^{35}$ Variation in rates among the same and different ethnic groups in diverse geographic regions warrant further study as this may provide clues to aetiology.

Our data do not support suggestions following the RRV-TV experience that wild-type rotaviruses are important aetiological agents for intussusception. ${ }^{10}{ }^{15} 16$ The epidemiology of children hospitalised with rotavirus infection in New Zealand appears distinct from those with intussusception. Rotavirus admissions are older, have a broader age peak, and show definite annual winter epidemics, compared with absent or small seasonal variations for intussusception. ${ }^{1428-32} 3536$ Studies from the United States and South America have comparable findings. ${ }^{8} 9131430$ However, ecological studies lack control for confounding and as they link population exposures to individual outcomes they are insensitive to strong, but infrequent associations. ${ }^{13} 25$ A case-control design addresses some of these limitations. A recent such study from Mexico found an association between intussusception and adenoviruses, but not with natural rotavirus infection. ${ }^{36}$

A strength of this retrospective study is that it analyses national data supplied in a standardised format. While private hospital discharges are not included, in New Zealand infants and young children with intussusception are rarely (if ever) treated in this setting. Case ascertainment and diagnostic specificity appear high, although for logistic reasons case validation was limited to two major paediatric units, each with a paediatric surgical service where diagnostic coding might be more robust than other centres. Other retrospective studies report $81-96 \%$ diagnostic accuracy for ICD coding in their intussusception patients. ${ }^{14}{ }^{31}{ }^{33}$ In contrast NZHIS procedure coding was incomplete for approximately half the cases precluding any reliable analysis of management. ${ }^{18}$

This study provides important national baseline data on intussusception for future rotavirus vaccine programmes in New Zealand. It suggests wild-type rotaviruses do not have a major role in triggering intussusception. As part of postlicensure agreements, prospective surveillance of intussusception should employ a standard case definition able to be used in different settings, which will allow comparisons between regions and populations $s^{37}$ and include nested casecontrol studies to help identify contributing genetic, ethnic, environmental, and infectious causes.

\section{ACKNOWLEDGEMENTS}

The New Zealand Rotavirus Study Group: R Pinnock, Starship Children's Health, Auckland; D Lennon, R Nicholson, Kidzfirst Hospital, South Auckland; D Graham, Waikato Hospital, Hamilton; K Grimwood, QS Huang, S Hook, I Gosling, C Cohet, Wellington Hospital; A Farrell, Kenepuru Hospital; P Leadbitter, Hutt Hospital, Wellington; D Teele, Christchurch Hospital, Christchurch, B Taylor, Dunedin Hospital, Dunedin. Work undertaken by the group was supported by a grant from the Health Research Council of New Zealand.

Y Chen received a summer studentship supported by the Surgical Research Trust and a non-directional grant from GlaxoSmithKline. We thank Rebecca Kay of NZHIS for assistance with case identification and Associate Professor Christopher Frampton from the Christchurch School of Medicine and Health Sciences for statistical advice.

\section{Authors' affiliations}

Y E Chen, S Beasley, Christchurch School of Medicine and Health Sciences, Christchurch, New Zealand

K Grimwood, Wellington School of Medicine and Health Sciences, Wellington, University of Otago, New Zealand

Funding: A \$2000 grant from GlaxoSmithKline (GSK) supported Y Chen during her summer studentship. GSK staff were not involved with the original concept and did not participate in the study design, conduct, data analysis, interpretation, or the writing of this research.

Competing interests: none declared 


\section{What is already known on this topic}

- A licensed rhesus-human reassortant tetravalent rotavirus vaccine was withdrawn because of an increased risk of intussusception

- There is limited understanding of the epidemiology and aetiology of intussusception

\section{REFERENCES}

1 Stringer MD, Pablot SM, Brereton RJ. Paediatric intussusception. Br J Surg 1992;79:867-75.

2 Bines JE, Ivanoff B. Acute intussusception in infants and children: a global perspective, WHO/V\&B/02.19. Geneva: Vaccines and Biologicals, World Health Organisation, 2002.

3 Hsu HY, Kao CL, Huang LM, et al. Viral etiology of intussusception in Taiwanese childhood. Pediatr Infect Dis J 1998;17:893-8.

4 Guarner J, DeLeon-Bonjorge B, Lopez-Corella E, et al. Intestinal intussusception associated with adenovirus infection in Mexican children. Am J Clin Pathol 2003;120:845-50.

5 Roberts L. Rotavirus vaccines' second chance. Science 2004;305:1890-3.

6 Ardern-Holmes S, Lennon D, Pinnock R, et al. Trends in hospitalization and mortality from rotavirus disease in New Zealand infants. Pediatr Infect Dis $J$ 1999;18:614-19.

7 Centers for Disease Control and Prevention. Withdrawal of rotavirus vaccine recommendation. MMWR Morb Mortal Wkly Rep 1999;48:1007.

8 Kramarz P, France EK, Destafano F, et al. Population-based study of rotavirus vaccination and intussusception. Pediatr Infect Dis J 2001;20:410-16.

9 Murphy TV, Gargiullo PM, Massoudi MS, et al. Intussusception among infants given an oral rotavirus vaccine. N Engl J Med 2001;344:564-72.

10 Konno T, Suzuki H, Kutsuzawa T, et al. Human rotavirus infection in infants and young children with intussusception. J Med Virol 1978;2:265-9.

11 Nicolas JC, Ingrand D, Fortier B, et al. A one-year virological survey of acute intussusception in childhood. J Med Virol 1982;9:267-71.

12 Mulcahy DL, Kamath KR, de Silva LM, et al. A two-part study of the aetiological role of rotavirus in intussusception. J Med Virol 1982;9:51-5.

13 Rennels MB, Parashar UD, Holman RC, et al. Lack of an apparent association between intussusception and wild or vaccine rotavirus infection. Pediatr Infect Dis J 1998;17:924-5.

14 Chang EJ, Zangwill KM, Lee $\mathrm{H}$, et al. Lack of association between rotavirus infection and intussusception: implications for use of attenuated rotavirus vaccines. Pediatr Infect Dis J 2002;21:97-102.

15 Robinson CG, Hernanz-Schulman M, Zhu Y, et al. Evaluation of anatomic changes in young children with natural rotavirus infection: is intussusception biologically plausible? J Infect Dis 2004;189:1382-7.

16 Peter G, Myers MG. Intussusception, rotavirus, and oral vaccines: summary of a workshop. Pediatrics 2002;110:e67.

17 Reid R, Kulkarni M, Beasley S. The potential for improvement in outcome of children with intussusception in the South Island. N Z Med J 2001;114:441-3.

18 Chen E, Grimwood K, Beasley S. Operative rates for acute intussusception in New Zealand. N Z Med J 2004;117:1202.

\section{What this study adds}

- Maori infants have intussusception rates significantly lower than New Zealand Europeans

- Wild-type rotaviruses are unlikely to be important causes of intussusception in New Zealand

19 Raudkivi PJ, Smith HLM. Intussusception: analysis of 98 cases. Br J Surg $1981 ; 68: 645-8$.

20 Strang R. Intussusception in infancy and childhood; a review of 400 cases. Br J Surg 1959;46:484-95.

21 Cooke DC, Lewis EC. A thirty-year survey of acute intussusception in childhood. Lancet 1960;7165:1359-64.

22 Dennison WM, Shaker M. Intussusception in infancy and childhood. Br J Surg 1970;57:679-84.

23 Kapikian AZ, Hoshino Y, Chanock RM. Rotavirus. In: Knipe DM, Howley PM, eds. Fields virology, Vol 2, 4th edn. Philadelphia: Lippincott-Raven, 2001:1787-833

24 Blakely T, Ajwani S, Robson B, et al. Decades of disparity: widening ethnic mortality gaps from 1980 to 1999. N Z Med J 2004;117:1199.

25 Glass RI, Bresee JS, Parashar UD, et al. The future of rotavirus vaccines: a major setback leads to new opportunities. Lancet 2004;363:1547-50.

26 Gay N, Ramsay M, Waight P. Rotavirus vaccination and intussusception. Lancet 1999;354:956.

27 Parashar UD, Holman RC, Cummings KC, et al. Trends in intussusceptionassociated hospitalizations and deaths among US infants. Pediatrics 2000;106:1413-21.

28 Chang H-GH, Smith PF, Ackelsberg J, et al. Intussusception, rotavirus diarrhea, and rotavirus vaccine use among children in New York state. Pediatrics $2001 ; 108: 54-60$.

29 Saez-Llorens $\mathbf{X}$. Intussusception and rotavirus vaccines: what is the background risk? Pediatr Infect Dis J 2004;23:363-5.

30 Perez-Schael I, Escalona M, Salinas B, et al. Intussusception-associated hospitalization among Venezuelan infants during 1998 through 2001 anticipating rotavirus vaccines. Pediatr Infect Dis J 2003;22:234-9.

31 O'Ryan M, Lucero Y, Pena A, et al. Two year review of intestinal intussusception in six large public hospitals of Santiago, Chile. Pediatr Infect Dis J 2003;22:717-21.

32 Nelson EAS, Tam JS, Glass RI, et al. Incidence of rotavirus diarrhea and intussusception in Hong Kong using standardized hospital discharge data. Pediatr Infect Dis J 2002;21:701-3.

33 Fischer TK, Bihrmann K, Perch M, et al. Intussusception in early childhood: a cohort study of 1.7 million children. Pediatrics 2004;1 14:782-5.

34 Justice F, Carlin J, Bines J. Changing epidemiology of intussusception in Australia. J Pediatr Child Health. In press.

35 Eshel G, Barr J, Heyman E, et al. Intussusception: a 9-year survey (19861995). J Pediatr Gastroenterol Nutr 1997;24:253-6.

36 Velazquez FR, Luna G, Cedillo $R$, et al. Natural rotavirus infection is not associated to intussusception in Mexican children. Pediatr Infect Dis 2004;23(suppl):S173-8.

37 Bines JE, Ivanoff $B$, Justice $F$, et al. Clinical case definition for the diagnosis of acute intussusception. J Pediatr Gastroenterol Nutr 2004;39:51 1-18. 